\title{
O CRACK NO CONTEXTO FAMILIAR: UMA ABORDAGEM FENOMENOLÓGICA ${ }^{1}$
}

\author{
Helca Franciolli Teixeira Reis², Thais Oliveira Moreira ${ }^{3}$
}

\footnotetext{
${ }^{1}$ Trabalho de Conclusão de Curso de Graduação em Enfermagem da Universidade Federal da Bahia (UFBA), em 2012.

${ }^{2}$ Mestre em Enfermagem e Saúde. Professora Assistente da UFBA. Bahia, Brasil. E-mail: helcareis@gmail.com

${ }^{3}$ Enfermeira. Bahia, Brasil. E-mail: thai_ufba@yahoo.com.br
}

\begin{abstract}
RESUMO: O presente estudo teve como objetivo conhecer o significado para a família da convivência diária com um membro usuário do crack. Trata-se de uma pesquisa qualitativa, descritiva, de natureza fenomenológica, que tomou como base para coleta dos dados empíricos a realização da entrevista fenomenológica com duas famílias de dependentes do crack, em um Centro de Atenção Psicossocial em Álcool e Outras Drogas. A análise e categorização das descrições vivenciais se processou à luz da analítica da ambiguidade, fundamentada na fenomenologia de Maurice Merleau-Ponty. Como resultados emergiram três categorias - Sobrecarga no cuidado: demonstração de amor e sofrimento; Peripécias e fantasias do usuário de crack: entre as dúvidas e as certezas; e A sombra infinda do crack à luz da cura pela fé. O estudo apresenta uma nova perspectiva sobre o uso do crack no contexto familiar, através da percepção intersubjetiva, reveladora das ambiguidades, que abre possibilidades para desvelar a vivência do outro.
\end{abstract}

DESCRITORES: Crack. Família. Relações familiares. Filosofia em enfermagem.

\section{CRACK IN THE FAMILY'S CONTEXT: A PHENOMENOLOGICAL APPROACH}

\begin{abstract}
The aim of this study is to know the meaning, for the family, of the daily contact with a member user of crack. This is a qualitative, descriptive and phenomenological study, whose empirical data collection was based on phenomenological interviews with two families of crack dependents in a Psychosocial Care Center on Alcohol and other Drugs. The analysis and categorization of experiential descriptions sued in the light of analytical of ambiguity, based on the phenomenology of Maurice Merleau-Ponty. As a result, three categories emerged - Overload care: demonstration of love and suffering; Mishaps and fantasies of crack user: between doubt and certainty; and The endless shadow of crack in the light of healing by faith. The study presents a new perspective on the use of crack in family context, through intersubjective perception, revealing the ambiguities, which opens possibilities to unveil the experience of another.
\end{abstract}

DESCRIPTORS: Crack. Family. Family relations. Philosophy, nursing.

\section{EL CRACK EN EL CONTEXTO DE LA FAMILIA: UNA APROXIMACIÓN FENOMENOLÓGICA}

RESUMEM: El objetivo de este estudio es conocer el significado, para la familia, apartir del contacto diario con un miembro consumidor de crack. Se trata de una investigación cualitativa, descriptiva, fenomenológica, que tomó como base para la recopilación de datos empíricos, la realización de entrevistas fenomenológicas con dos familias de dependientes de crack en un Centro de Atención Psicosocial en Alcohol y otras drogas. El análisis y categorización de las descripciones experienciales demandaron a la luz de la analítica de la ambigüedad, basada en la fenomenología de Maurice Merleau-Ponty. Como resultados surgieron tres categorías - Sobrecarga en el cuidado: demostración de amor y sufrimiento; Peripécias y fantasías de los consumidores de crack: entre las dudas y las certezas; y La sombra interminable de crack a la luz de la curación por la fe. El estudio presenta una nueva perspectiva sobre el consumo de crack en el contexto familiar, a través de la percepción intersubjetiva, reveladora de las ambigüedades, que abre posibilidades para dar a conocer la experiencia de otro.

DESCRIPTORES: Crack. Familia. Relaciones familiares. Filosofía en enfermería. 


\section{O EMERGIR DO OBJETO DE ESTUDO}

O crack chegou ao Brasil no final da década de 80, em São Paulo-SP, e por muitos anos o seu consumo esteve vinculado a grandes metrópoles. No entanto, esta tendência não é mais vigente em tempos atuais, pois o uso do crack ultrapassou os limites das fronteiras metropolitanas e estendeu-se por todo o país. ${ }^{1}$

Nesta perspectiva, "o crescimento do consumo do crack no Brasil tornou-se um fenômeno de saúde pública, sendo hoje chamado de epidemia do crack" . 2:337 Assim, uma atenção especial e particular deve direcionar-se aos sujeitos dependentes do crack, visto presumível correlação do seu consumo com agravos do Sistema de Saúde como, por exemplo, a violência, em que, possivelmente, geram-se impactos que perpassam as dimensões subjetivas e estendem-se por esferas amplas, tais como a família e a sociedade com um todo, por vezes onerosos aos serviços de saúde.

Todo esse paradigma sinaliza a possível necessidade de tecnologias de cuidado que versam sobre práticas de saúde de qualidade, como formas de serviços abrangentes à contemporaneidade do atual cenário de uso de drogas, diante de um novo olhar sob a saúde mental, ideias estas embasadas na Reforma Psiquiátrica. ${ }^{3}$

A Reforma Psiquiátrica, como marco político da reconstrução da saúde mental, busca um novo olhar para o adoecimento psíquico, para além do modelo predominante hegemônico e hospitalocêntrico, no qual prepondera o sistema asilar/ repressor, de cunho punitivo. Pauta-se, assim, em uma assistência humanizada e qualificada perante o sujeito que sofre mentalmente, também diante do uso e abuso de drogas.

Com a criação dos Centros de Atenção Psicossocial Álcool e Drogas (CAPSs AD) (Portaria n. 336/2002), ${ }^{4}$ o combate às drogas, em especial o crack, anteriormente sob a responsabilidade policial, passou a ser pensado na perspectiva da saúde, com ênfase na ação aos efeitos do consumo das drogas. Assim, incorporam-se as lícitas, como bebidas alcoólicas e tabaco, à área da saúde mental, além das drogas reconhecidas como ilícitas, a exemplo do crack. $^{5}$

Diante do problema e desafios impostos pela dependência ao crack, o governo lançou o Plano Integrado de Enfrentamento ao Crack e outras Drogas, estabelecido pelo decreto n. 7179 de 20 de maio de 2010, em seu Art. $2^{\circ}$. Relata-se que um dos seus objetivos é estruturar, integrar, articular e ampliar as ações voltadas à prevenção do uso, tratamento e reinserção social de usuários de crack e outras drogas, contemplando a participação dos familiares e a atenção aos públicos vulneráveis, entre outros, crianças, adolescentes e população em situação de rua. ${ }^{6}$

Diante dessa conjuntura, entende-se a importância da inserção da família no contexto terapêutico aos usuários de crack e outras drogas, uma vez que é no contexto familiar que se vivencia as consequências da dependência a estas substâncias. Nesse entendimento, bem mais do que o sujeito que sofre, temos um sistema que possivelmente fragiliza-se e desestabiliza-se diante da dependência ao crack. Tal pensamento, numa linguagem fenomenológica, visa compreender o fenômeno na perspectiva de quem vive, neste caso, a partir da unidade que sofre como um todo, ou seja, a família.

A motivação em pesquisar tal temática partiu da experiência da Atividade Curricular em Comunidade (ACC), intitulada "Cuidados interdisciplinares à saúde da família em conviabilidade com o sofrimento mental". Trata-se de uma modalidade curricular da Universidade Federal da Bahia (UFBA), Instituto Multidisciplinar em Saúde, Campos Anísio Teixeira (IMS/CAT), que versa sobre a abordagem qualitativa/interdisciplinar as famílias de Pessoas com Sofrimento Mental (PSMs), advindo do uso de crack e outras drogas. Na ACC em questão tivemos a oportunidade de experimentar alternativas metodológicas que viabilizavam a compreensão de problemas e temas relevantes àquelas famílias, participantes da proposta, no campo do processo saúde-adoecimento mental, de maneira a colaborar para o processo de conviver de seus membros, numa perspectiva de reconhecimento do outro a partir de si mesmo, através da intersubjetividade, defendida pela fenomenologia.

Assim, emergiu a seguinte questão de pesquisa, que orientou esse estudo: o que significa, para a família, conviver com um membro dependente do crack?

\section{OBJETIVO}

Compreender o significado, para a família, da convivência com um membro usuário do crack. 


\section{METODOLOGIA}

Trata-se de uma pesquisa qualitativa, descritiva, fundamentada na fenomenologia da experiência de Maurice Merleau-Ponty, desenvolvida no CAPS AD de um município da Região Sudoeste da Bahia, com duas famílias de dependentes do crack, cadastrados naquele serviço.

Ressalta-se que, nesse estudo, trabalhamos com a família nuclear, ou seja, pais, mães e filhos, que se concretizavam na convivência de maneira interativa e dinâmica, na construção do seu sistema de valores sociais, conceitos e saberes.

Como critérios de inclusão na pesquisa foram considerados os seguintes aspectos: famílias que residem no município, que possuem um ou mais membros dependentes de crack, acompanhados no CAPS AD; ter familiares que participam dos encontros grupais na "Roda de Vidas Viva!" (Rodas de conversa - atividades da ACC IMS/ CAT/UFBA); ter familiares que frequentam o CAPS AD por mais de seis meses; maiores de 18 anos; e que participam do cuidado direto ou indireto ao membro familiar dependente de crack.

Já os critérios de exclusão na pesquisa foram a falta de disponibilidade de tempo em participar de todos os encontros para a produção dos dados e a limitação cognitiva de alguns membros das famílias, além da não adequação aos aspectos de inclusão acima listados. Nesse pensar, as duas famílias do estudo foram constituídas de genitores (pais e mães) que conviviam diariamente com seus filhos dependentes de crack, em tratamento no CAPS AD. Acrescenta-se que o número de participantes, familiares, não foi pré-estabelecido, uma vez que o estudo de natureza fenomenológica considera a essência do que se mostra e não a quantidade de sujeitos ou encontros realizados. ${ }^{7}$

A produção dos dados ocorreu no primeiro semestre de 2012, após aprovação do protocolo do projeto de pesquisa pelo Comitê de Ética em Pesquisa (CEP) da Universidade Estadual do Sudoeste da Bahia (UESB), sob o parecer n. 200/ 2011. Os sujeitos da pesquisa aceitaram, voluntariamente, o convite para participar do estudo, assinando um Termo de Consentimento Livre e Esclarecido.

A presente pesquisa tomou como base para produção dos dados a realização da entrevista fenomenológica grupal. Por se tratar de um estudo fenomenológico, utilizamos questões flexíveis e disparadoras para o diálogo. Tais questões estavam relacionadas à temática do estudo e nortearam as discussões dos encontros, de forma a deixar aparecer os fenômenos que responderiam à questão de pesquisa. Em cada um desses encontros, mediados pela intersubjetividade e empatia, duas questões do roteiro foram escolhidas e discutidas pelo grupo. Esses encontros foram previamente agendados com os participantes da pesquisa e realizados na sala de terapia grupal do CAPS AD, com uma duração média de duas horas para cada um. Os familiares foram identificados com nomes de pedras preciosas, conforme a escolha dos mesmos, a fim de preservar os seus anonimatos. Enfatizamos que os participantes deveriam sentir-se a vontade para falar livremente sobre a convivência em família, com um membro dependente de crack. Por meio da entrevista abriram-se possibilidades inéditas, oportunizadas pelas palavras, a partir da experiência de campo.

Assim, conduzir os encontros com os familiares constituiu-se em uma experiência intersubjetiva, cujas vivências foram compartilhadas entre todos os sujeitos envolvidos, mostrando que no ambiente familiar acontece o conviver de seus membros e, neste ambiente, há descobertas para a construção de conhecimento.

As entrevistas gravadas foram ouvidas por diversas vezes e transcritas de maneira mais fidedigna possível, a fim de proceder à etapa seguinte que consistiu na análise das descrições vivenciais, tomando como base a analítica da ambiguidade. Esta tem como matriz teórica a redução fenomenológica eidética de Husserl, clássico precursor do método fenomenológico, que se trata de suspender as teses que acreditam ser as coisas em si mesmas. ${ }^{8}$ A analítica da ambiguidade versa, basicamente, em consentir que os fenômenos se mostrem em si mesmos a partir de si mesmos, na perspectiva de que aquilo que se encontra irrefletido passe à reflexão, articulando o pensamento como objeto percebido, não do ponto de vista de algo acabado, mas como algo que se abre a outras possibilidades. ${ }^{9}$ Ainda, a analítica da ambiguidade busca perceber o vivido intencional que antecipa a articulação da linguagem, ou seja, encontrar no texto, o sentido essencial subjacente, isto é, suspender as teses de que as coisas já são em si mesmas. ${ }^{9-11}$

Sendo assim, nos encontros foi possível relacionar-se com os familiares de tal maneira que possibilitou-nos a captura do dito e o não dito, ou seja, outros perfis mostraram-se, pois além do discurso oral, observou-se o silêncio, os gestos, as atitudes, bem como, respeitou-se o espaço e o tempo dos familiares. ${ }^{12}$ 


\section{RESULTADOS OBTIDOS A PARTIR DA ANALÍTICA DA AMBIGUIDADE: O DESVELAR DO FÊNOMENO}

A experiência perceptiva de análise das descrições vivenciais (dados coletados) dos familiares de usuários de crack sobre as relações de convivência com um membro dependente, desvelou-se em fenômenos e esses se mostraram como aparências, sempre em perfil, trazendo consigo fundos que continham muitos outros perfis, fazendo com que percebêssemos suas ambiguidades. Assim, construímos as categorias de análise, as quais perpetram essas ambigüidades.

\section{Categoria 1 - Sobrecarga no cuidado: demonstração de amor e sofrimento}

Nessa categoria de análise percebemos que o familiar descreve em seus discursos uma "sobrecarga" do cuidar no convívio com o membro dependente do crack, por vezes impregnada pelo sofrimento da família como um todo. Apesar disso, nada os impede de amá-los incondicionalmente, e o "amor" desvela- se como a justificativa e consequência natural de um sentimento maior de um familiar por um ente querido.

Teoricamente, existem dois tipos de sobrecarga, classificadas como objetiva e subjetiva. A primeira é representada pela modificação da rotina familiar, tanto social, quanto profissional, desgastes financeiros, cuidados despendidos ao ser cuidado, comportamentos inoportunos, bem como agressões físicas e/ou verbais. A segunda é caracterizada por como a família percebe e avalia a sua conduta, diante da situação. ${ }^{13}$

O familiar, ao descrever sua convivência com um membro usuário de crack, a desvela como uma sobrecarga quando faz referência ao cuidado a essa pessoa, em que reporta o sofrimento vivenciado pela família e as situações de preocupação que tal experiência impetra. Mas, ao mesmo tempo, também esboça os sentimentos de amor manifestado na relação de cuidado e desvelo. Assim, veremos nos discursos seguintes:

para mim o significado de conviver com um membro dependente de crack é preocupação, porque ele tá bonzinho, sãozinho, bonitinho, cheirosinho, e aí sai e você não sabe como vai voltar [...] muitas vezes ele volta bem [...] e muitas vezes, no meu caso [...], que ele é compulsivo, ele chega um bagaço, derrubado. Então é preocupação, para mim e minha família, a gente nunca sabe quando é que ele tá bom [...]. A cabeça a gente nunca sabe como é que tá. Meu marido fala assim: 'se nós que somos pais não aguentarmos, quem é que vai aguentar? Nós que temos que aguentar'. É por amor, que se não for por amor, a gente não aguenta não! [...] (Ametista, mãe de Rubi).

a gente às vezes sente assim, tão impotente, tão humilhado, que você vê o filho sai todo arrumado, aí chega de pé descalço.Uma vez vocês [vira-se para o marido] encontraram ele na rodoviária [...], descalço, com a roupa toda suja! Fomos arrumar um lugar pra ele tomar um banho, um hotel, o povo não aceitou, por causa da situação que ele tava (Turquesa, mãe de Quartzo).

Os discursos das participantes sobre seus sentimentos e significados da convivência com um usuário de crack na família remetem à ideia de fenômeno, lembrando que o mesmo surge como uma figura que traz consigo um fundo contendo várias figuras, que podem passar despercebidas e comprometer sua compreensão. A respeito da noção de fenômeno, Merleau-Ponty ${ }^{14}$ aborda que o mundo apresenta-se sempre em perspectivas, mas estas carregam consigo todas as demais sem que tenhamos de elaborar; e é justamente esta a idéia de fenômeno; aquilo que surge desde si mesmo, tal como é em si mesmo. Porém, não como algo isolado ou acabado, e sim, como uma figura que sofre desdobramentos, de onde se considera que toda percepção é uma percepção de fenômeno. ${ }^{14-15}$ Logo, o fenômeno constitui-se como um processo que aparece carregando consigo uma história a ele atrelado e, nesta perspectiva, trata-se de um exercício instaurado no mundo da vida.

Sendo assim, ao reportarmos as descrições vivenciais anteriores, percebemos o quanto a convivência é evidenciada como sinônimo de preocupação, não só para a genitora, mas para todos os membros da família. A repetição do verbo "aguentar", no primeiro discurso, revela o quanto esse convívio, por vezes, parece penoso e complicado e, ao mesmo tempo, o sentimento de amor pelo ente querido, mostra o porquê de conseguirem "aguentar", pois segundo o familiar, se não fosse pelo amor, a mesma acredita que não suportaria.

Outro discurso que chama a atenção foi o fato da genitora fazer a comparação entre a dor gerada pela morte de um filho, com o sofrimento causado pela dependência de crack do outro filho, declarando que esta última convivência transcende a primeira no que se refere ao maior dano que ela gera na família inteira, conforme destacamos a seguir:

[...] eu vou falar uma coisa aqui, um pouco pesado: eu perdi um filho com 18 anos, em um acidente, 
sofri demais, porque perder um filho, não existe uma dor pior. Eu mesmo falava pra meu marido que agora tô vivendo $50 \%$ da minha vida! Você acredita que o sofrimento desse outro [o dependente] é tamanho que eu, às vezes, nem lembro que perdi esse filho? Esqueci a dor? É pior do que a morte! Eu tenho certeza, para mim é! Uma vez eu falei: que Deus é esse, que meu filho tão lindo, tão maravilhoso, e tanta gente ruim aí? Mas hoje eu digo com toda sinceridade, existe coisa pior do que a morte! Eu já aprendi a conviver com essa separação física, que a gente não aprende nunca, eu sentia o cheiro do perfume dele, ele roubava rosa no jardim pra me dar. Nós sofremos muito com a morte dele, saí da escola, pensei que não ia resistir, porque não tinha condição de olhar pra sala que ele estudava. Mas hoje lhe digo: conviver com alguém usuário de cracké muito pior que a morte! (Turquesa, mãe de Quartzo).

É culturalmente aceito o fato da finitude da vida; a morte é percebida como um "descanso". Quem morre suponha-se que esteja bem. Já o filho vivo, no entanto, dependente químico, não se encontra bem. Ele sofre e, consequentemente, toda sua família. Esses necessitam de cuidado, uma vez que os familiares dizem ser difícil e penoso ver um filho na situação de dependente.

Fica evidente aqui o quanto a existência de um membro na família dependente de crack repercute em questões que trazem sofrimento naquele ambiente. $\mathrm{O}$ familiar chega a pontuar que se acostuma com a falta gerada por uma morte, mas não se acostuma com um filho que também sofre com tal dependência. Observa-se que esse sofrimento vai além do sofrimento do familiar cuidador, transcende o perceber-se enquanto ser isolado, mas evidencia a preocupação com o outro, o cuidado que se desvela em amor pelo filho dependente químico, bem como por si próprio, pelo outro eu mesmo.

Cuidar é uma atitude essencial ao ser humano, exprime uma consideração pelo outro ser cuidado ou pelo outro eu mesmo e por suas necessidades. ${ }^{16}$ Essa dinâmica permite compreender a relação com o outro. Nesta, a fenomenologia merleaupontyana acrescenta que o eu e o outro não se distingue, o que implica em dizer que a identidade, como generalidade de nosso corpo, e a percepção do outro, repousam sobre a "universalidade do sentir"; portanto, somos coextensivos com tudo o que vemos, ouvimos e compreendemos e, por isso, somos uma totalidade; a todo instante sentimos que nos sentem, e nos sentem enquanto sentimos. ${ }^{17}$

Observamos que o processo de cuidar revela que apesar dos familiares sentirem-se sobrecar- regados e estressados na convivência com um membro dependente químico, podendo implicar em consequências para a sua saúde física e mental, eles conseguem encontrar sentido no cuidar. $\mathrm{O}$ cuidado então compreendido numa perspectiva mais otimista, que não apenas uma experiência de sofrimento. ${ }^{17}$ Isso é o que conhecemos por fenômeno, algo que se apresenta em perfil na experiência perceptiva, mas trás consigo outros perfis, os quais se desvelam como a experiência de observar um cenário em que, embora nos focamos em uma figura, podemos contar com a coexistência das demais. ${ }^{18}$

Assim, a convivência com o membro dependente de crack desvela uma sobrecarga no cuidado que de diversos meios aflige e desestrutura a dinâmica familiar. No entanto, acima de tudo, existe um amor incondicional que poderia ser classificado como motor na condução da convivência com o usuário de crack. Destarte, independente de toda a sobrecarga, o amor fraternal sempre sobrepõe e guiará as ações dessas famílias para com o membro dependente do crack.

\section{Categoria 2 - Peripécias do usuário de crack: entre as dúvidas e as certezas}

Esta categoria de análise evidencia que a necessidade do consumo compulsivo do crack pelo dependente leva-o a "mentir" para o seu familiar. Entretanto, ao mesmo tempo em que ele mente, criando histórias por vezes consideradas pelos familiares como mirabolantes, porém momentaneamente convincentes, em outro momento ele manifesta a precisão de falar a "verdade", a fim de corrigir e justificar as suas atitudes. Essas características de comportamento ficam perceptíveis nos discursos seguintes:

[...] nos primeiros tempos que os filhos se tornam dependentes, eles começam com mentirinhas de falar: 'vou para casa de amigo'; ele nunca foi criado em casa de amigo, nem casa de fora pra ele ir dormir [...] começa as mentiras e a gente começa a descobrir [...]. Depois o meu começou com os traficantes. Uma vez faltou dinheiro, ele roubou um cachorro, e o dono do cachorro chegou lá em casa bravo. Meu marido nunca tinha presenciado aquilo! Aí, quando cheguei (do trabalho), ele tava já drogado: [...] 'filho, vamos buscar o cachorro porque senão seu pai não aguenta ouvir esses desaforos aqui em casa'! [...] Fomos numa boca de fumo [...]. Cheguei lá, peguei esse cachorro, morrendo de medo [...]. Entregamos o cachorro para o dono e ainda tivemos que pagar o traficante. Pra você ver o que o crack leva a pessoa [...]. 
A mentira, ela irrita os familiares, os pai. Ele acha que tá enganando a gente, que estamos comendo os agás, que a gente é bestinha! É uma característica do usuário de crack, eles acharem que enganam (Ametista, mãe de Rubi).

[...] tem hora que ele fala uma coisa pra mim, com tanta convicção, que eu vou lá e acredito, eu caio. Aí depois eu fico: como é que esse menino foi inventar isso? Tem hora que eu fico pensando que tem alguém dentro dele, porque não é possível uma pessoa só, inventar tantas coisas, que ele inventa e fala (Topázio, pai de Quartzo).

Nos discursos de Ametista e Topázio, as mentiras desvelam-se na convivência com o membro usuário de crack desde cedo, no início da adicção à droga e transcende por todas as próximas fases da dependência, a ponto do familiar cogitar a possibilidade de um "outro ser" (espiritual) ser o responsável pela origem de tantas mentiras. $\mathrm{O}$ objetivo das mentiras nos parece claro, a necessidade insaciável do consumo da droga, a fissura pelo crack; fica difícil confiar no membro dependente do crack, pois a dúvida entre a verdade e a mentira diante de seus discursos e atitudes sempre vai existir. Percebe-se também no primeiro discurso uma atitude inusitada, o roubo de um cachorro em troca da manutenção do vício, onde tanto a vida de Rubi, como de sua mãe, Ametista, é colocada em risco. Tendo em vista que ambos precisaram adentrar em ambiente considerado perigoso, hostil e temeroso, a "boca de fumo", para resgatar o cachorro e devolvê-lo ao dono que estava bastante chateado, bem como livrar o próprio filho da dívida com traficantes e punição social pelo roubo.

A "fissura" ao crack pode ser considerada como um dos pilares responsáveis pela dependência à droga, o que se associa diretamente com a prática constante da mentira, especialmente no caso da dependência do crack. Esta droga tem efeito rápido e consumo de caráter compulsivo. Segundo informações pesquisadas com dependentes do crack, a fissura desvela-se para eles como algo negativo, deflagrada frequentemente por situações que fazem alusão ao crack, necessidade de não sentir o desconforto causado pela ausência do crack no organismo e no próprio momento do uso do crack embalado pelo desejo de consumir mais, até que os mesmos entrem na fase de esgotamento tanto físico, quanto psicológico e, consequentemente, financeiro. ${ }^{19}$

O desejo irrefreável pela droga e a necessidade constante do uso conduz os dependentes a atividades como venda dos seus objetos pessoais, familiares, roubos, sequestros, dentre outros. ${ }^{20} \mathrm{Tal}$ situação veremos nos discursos seguintes:

[...] ele já comprou um tênis de tarde e na mesma tarde ele chegou a oferecer por cinco reias ao cara da venda, que viu o trem tão barato que falou: 'não vou comprar'. Olha, o crack só leva as pessoas a coisas que você não é capaz nem de imaginar, nem sonhar. [...] fora disso, é uma ótima pessoa (Topázio, pai de Quartzo).

[...] quando ele tinha 17 anos, antes de ser internado, ele planejou o sequestro dele junto com o traficante. Eram 50 reais; aquele tempo valia, né? Aî eu fui lá entregar o dinheiro. Meu amigo ficou de longe me olhando, prestando atenção pra me defender, caso o sequestrador viesse fazer qualquer coisa. Quando vejo, vem ele mais traficante numa bicicleta, aí o delegado, meu amigo, depois, me procurou e falou: 'eu não achei nada não, que eu nunca vi o sequestrado carregar o sequestrador!' Pois todo mundo tinha caído lá em casa, até o delegado achou que era mesmo! (Ametista, mãe de Rubi).

[...] um dia, eu tava deitada, assistindo televisão, aí [...] entra ele e mais dois e falou assim: 'pode pegar aí moço' [disse o filho]! Eu falei: o que é isso? Ele disse: 'cala a boca'! Ele trocou o DVD por uma arma, acho que tinha outra coisa também. Aí eu fui lá, quando eu vi o carro vermelho, que to anotando a placa, ele botou a arma em mim, assim, não faltou nem quatro dedos, eu falei assim: pode atirar, atira, pode atirar porque eu, pra mim, já tô uma pessoa morta e você para mim já é uma pessoa morta e não existe mais, pode atirar! E ele ficou assim, oh [fez o gesto com a mão em arma em punho], bem uns dois ou três minutos assim, $e$ não atirou. Para mim o que significa conviver com um membro assim é a morte. Eu não sentia nada por ele, eu senti nesse dia que não era ninguém para mim (Turquesa, mãe de Quartzo).

Ametista e Turquesa desvelam a desvalorização financeira dos seus próprios bens, como da família como um todo. Esta situação é caracterizada pela venda de um objeto pessoal, o tênis, e o sequestro armado, muito provavelmente com o objetivo de quitar uma dívida com o traficante, onde mais uma vez a mentira fora posteriormente revelada. Ressalta-se que o objetivo de atender a própria necessidade do consumo do crack, muitas vezes o dependente químico pratica atividades ilícitas, as quais incluem extorquir dinheiro e/ ou objetos da própria família, uma ligação direta com a criminalidade que muito preocupa os seus familiares. $^{20}$

Aparentemente, os indivíduos dependentes do crack se utilizam de estratégias no relaciona- 
mento com os seus familiares, bem como com a sociedade em geral, consideradas pelos participantes da pesquisa como atitudes que distorcem da realidade.

Uma vez eu fui levar o meu pra internar em São Paulo, aí um primo meu arrumou um carro, eu fui levar. Mas ele contou um papo tão bonito, pra as duas pessoas que iam no carro, que eles acharam que eu tava mentindo, falaram assim: 'meu Deus, que mulher injusta essa! Vai levar o filho para internar, um menino bom desse jeito'. Ele foi sãosinho daqui até lá! Na volta, eles me falaram: 'dona Ametista, eu achei que a senhora foi injusta!'. Vai viver com ele, então! É porque você não sabe o que tá passando com ele, você não sabe pra você falar! Jamais eu queria gastar o dinheiro com clínica, jamais! Já pensou, gente! A gente pagar pra o filho ficar fora. Se eu fosse fazer isso, eu tava boa de morrer! (Ametista, mãe de Rubi).

O usuário do crack, para se relacionar bem com as outras pessoas, muitas vezes desenvolve um perfil de caráter mentiroso e manipulador, em que, provavelmente, os sujeitos têm a consciência de suas atitudes e, inclusive, as reconhece como responsáveis na ausência de confiança. ${ }^{19}$ Assim, percebemos uma distorção da realidade por outras pessoas que não convivem diariamente com o dependente químico, a ponto de duvidarem da necessidade do tratamento e julgarem a atitude de seus familiares cuidadores como injusta.

A convivência se configura com um espaço de abertura ao outro, onde há possibilidades de reconstrução de vínculos, permeados por conflitos inerentes à família, e se manifesta a ajuda mútua entre o familiar cuidador e o dependente químico. O familiar reconhece o outro como parte de si e compartilha dos seus medos, aflições, desejos e mecanismos de se relacionar. Igualmente, as inferências feitas por Ametista sobre o comportamento do filho e a necessidade de internação devem ser consideradas como relevantes, visto que ela é quem convive diretamente com esse membro e quem sente a necessidade de tratamento especializado ou não.

Podemos perceber que as atitudes/peripécias do membro usuário de crack são cercadas por dúvidas e certezas, verdades e mentiras, que geram um sofrimento ainda maior e contribuem para a manutenção de um ambiente familiar fragilizado. Já a elaboração dos laços de confiança configuraria como um passo inicial para o estabelecimento de um melhor relacionamento interpessoal entre os componentes da família.

\section{Categoria 3 - A sombra infinda do crack à} luz da cura pela fé

Nessa categoria de análise descrevemos a fé, a representação da espiritualidade, como a única alternativa de cura e esperança evidenciada pelos familiares, apesar de compreenderem que a sombra da dependência a droga sempre estará presente na trajetória de suas famílias. A fé os faz suportar as dificuldades na convivência com o membro dependente do crack e a conviver diariamente com "a sombra infinda do crack", posto a sua presença indesejável no dia a dia da família diante da possibilidade sempre presente da recaída.

A religiosidade e a fé têm sido apontadas em alguns estudos como mecanismos eficientes e benéficos nas enfermidades, pois auxilia positivamente na compreensão das mudanças sociais e psicológicas consequentes do processo de adoecimento, com melhoras, inclusive da qualidade de vida do sujeito enfermo. ${ }^{21}$

Ao nos voltarmos para a convivência dos participantes da pesquisa, percebemos que os mesmos vislumbram a fé como a alternativa e o motivo que fazem com que eles suportem a sobrecarga que é conviver com o membro dependente do crack. Para os familiares, os entes queridos só ficarão bem, curados pela fé, independente da ajuda profissional que eles possam vir a ter.

Tem pessoas que não vivem buscando a fé. Mas, buscando em Jesus, eu vivo bem, porque vivo na fé, confiada em Deus, orando ao Senhor. Eu oro quase 24 horas por dia, e confio pela fé, eu só vivo pela fé em minha casa, é só a fé que me sustenta; [...] imagine quem não busca essa fé, que não se agarra em Jesus nosso Salvador, deve ser muito difícil. Eu confio no Senhor, sei que um dia o meu vai ficar bom, pela fé, porque pelo homem é muito difícil, por ele mesmo, sem Jesus, é difícil gente! (Ametista, mãe de Rubi).

Às vezes eu vou lá e volto: tem jeito não! Mas Deus vai olhar pra ele. Eu falo: oh, meu Deus, o Senhor me deu essa criança, me ajuda, me ajuda a livrar essa criança desse mal, me dê força! (Topázio, pai de Quartzo).

Percebemos nos discursos que os familiares confiam com veemência em uma força maior representada aqui por Deus. Buscam na fé a solução ou amenização dos problemas e adversidades da vida, gerados pela dependência química; buscam, sobretudo, um alento para suportar as provas da vida, aqui representadas pela sobrecarga que é conviver com um membro dependente do crack, como discutido anteriormente. 
Podemos questionar também qual é o verdadeiro papel dos profissionais de saúde frente a uma cura que só acontecerá, na percepção dos familiares, através da fé, o que nos leva a indagar se realmente os serviços terapêuticos estão sendo efetivos no auxílio ao dependente de drogas e a sua família, bem como qual é a nossa postura como profissionais frente a essa realidade. Tal fato nos leva a refletir se as famílias são contempladas em sua inteireza, uma vez que as peculiaridades inerentes a esta, como a própria cultura, a religiosidade e expressão de fé, não são de fato consideradas.

No segundo discurso, percebemos que o filho é visto "como um presente divino", onde roga a ajuda do próprio Deus para recuperação do filho e possibilidade para a reconstrução da vida do mesmo. Assim, a convivência pode ser entendida como uma permissão divina, que auxilia e oferece forças na convivência com o membro, empoderando- o no cuidar, na certeza do "eu posso" diante das adversidades do cuidar. ${ }^{17}$

A sombra infinda do crack parece então tornar-se menos escura, pois os caminhos a serem trilhados são conduzidos pela fé, e nela está o caminho para a cura, esperança e salvação do ente querido dependente de crack.

\section{A INAPREENSÃO DOS VIVIDOS: CONSIDERAÇÕES FINAIS}

O estudo desvelou que a convivência familiar com um membro usuário do crack não é fácil nem simples e gera sobrecarga para a família inteira, mais precisamente sobre aqueles responsáveis pelo cuidado direto. Em contrapartida, embora exista toda essa sobrecarga, a família não deixa de amar o seu familiar dependente do crack e deseja sempre que a sua vida prossiga da melhor maneira possível para caminhos que os distanciem da droga; sempre cuidando do mesmo com todo carinho e afeto necessário. Assim, o amor fraternal se configura como algo que está muito além de qualquer conflito familiar.

Ratifica-se que outra dificuldade encontrada na convivência com o membro dependente do crack, descrita pelos familiares, é a "facilidade" com que esse ente querido tem em mentir, pela necessidade do consumo da droga. Como consequências, as suas atitudes na convivência com o familiar suscitam sempre dúvida sobre a veracidade dos fatos, já que a família não sabe se deve confiar ou não naquele familiar.
A fé mostrou-se muito presente nas relações de convivência, foi compreendida como uma estratégia que contribui positivamente para a superação de situações adversas e conflituosas com o membro dependente do crack. Dessa forma, ela caracterizou-se, nesse estudo, como uma força motriz que impulsiona as famílias, em especial os familiares cuidadores, a suportarem a sobrecarga inerente à presença infinda da sombra do crack em seus contextos.

A pesquisa em questão permitiu compreender que a experiência perceptiva revela-se como fenômenos, os quais mostram perfis que fazem emergir outros perfis, onde a fonte de construção de saber não se esgota, pois se olharmos para o mesmo fenômeno mais vezes, certamente faremos novas inferências sobre os fenômenos, uma vez que os mesmos nunca se desvelam de forma plena, não sendo possível alcançar ou esgotar todas as possibilidades de reflexão sobre como se configura a presença do crack no contexto familiar.

\section{REFERÊNCIAS}

1. Dualibi LMFB. Revisão sistemática: perfil dos usuários de cocaína e crack no Brasil [dissertação]. São Paulo (SP): Escola Paulista de Medicina da Universidade Federal de São Paulo. Mestrado em Ciências; 2010.

2. Pulcherio G, Stolf AR, Pettenon M, Fensterseifer DP, Kessler F. Crack - da pedra ao tratamento. Rev AMRIGS. 2010 Jul-Set; 54(3):337-43.

3. Ministério da Saúde (BR), Secretaria de Atenção à Saúde, Coordenação Geral de Saúde Mental. Reforma psiquiátrica e política de saúde mental no Brasil. Brasília (DF): MS; 2005.

4. Brasil. Portaria n. 336, de 19 de fevereiro de 2002. Estabelece os Centros de Atenção Psicossocial nas seguintes modalidades: CAPS I, CAPS II e CAPS III. Diário Oficial da União, 19 fev 2003. Seção 1.

5. Organização Mundial da Saúde (OMS). Relatório sobre a saúde no mundo 2001. Saúde mental: nova concepção, nova esperança. Genebra (CH): OMS; 2001.

6. Brasil. Decreto n. 7119 de 20 de maio de 2010. Institui o Plano Integrado de Enfrentamento ao Crack e outras Drogas, cria o seu Comitê Gestor, e dá outras providências [online]. Presidência da República Casa Civil, 20 maio 2010 [acesso 2011 Set 24]. Disponível em: http:/ / www.planalto.gov.br/ ccivil_03/_Ato2007-2010/2010/Decreto/D7179.htm

7. Boemer MR. A condução de estudos segundo a metodologia de investigação fenomenológica. Rev Latino-Am Enferm. 1994 Jan; 2(1):83-94. 
8. Sena ELS, Gonçalves LHT. Vivências de familiares cuidadores de pessoas idosas com doença de Alzheimer: perspectiva da filosofia de Merleau-Ponty. Texto Contexto Enferm. 2008 Abr-Jun; 17(2):232-40.

9. Sena ELS, Carvalho PAL, Reis HFT, Rocha MB. Percepção de familiares sobre o cuidado à pessoa com câncer em estágio avançado. Texto Contexto Enferm. 2011 Out-Dez; 20(4):774-81.

10. Sena ELS, Gonçalves LHT. Intercorporeidade na experiência do cuidado: familiar cuidador e portador da doença de Alzheimer. In: Silva AL, Gonçalves LHT, organizadores. Cuidado à pessoa idosa: estudos no contexto luso-brasileiro. Porto Alegre (RS): Sulina; 2010. p. 193-218.

11. Sena ELS, Gonçalves LHT, Müller Granzotto MJ, Carvalho PAL, Reis HFT. Analítica da ambiguidade: estratégia metódica para a pesquisa fenomenológica em saúde. Rev Gaúcha Enferm. 2010 Dez; 31(4):769-75.

12. Carvalho AS. Metodologia da entrevista: uma abordagem fenomenológica. $2^{\mathrm{a}}$ ed. Rio de Janeiro (RJ): Agir; 1991.

13. Galera SAF, Zanetti ACG, Ferreira GCS, Giacon BCC, Cardoso L. Pesquisas com famílias de portadores de transtorno mental. Rev Bras Enferm. 2011 Jul-Ago; 64(4):774-8.

14. Merleau-Ponty M. A prosa do mundo. São Paulo (SP): Cosac \& Naify; 2002.
15. Sena ELS, Boery RNSO, Carvalho PAL, Reis HFT, Marques AMN. O alcoolismo no contexto familiar: um olhar fenomenológico. Texto Contexto Enferm. 2011 Abr-Jun; 20(2):310-8.

16. Boff L. Ética e eco-espiritualidade. Campinas (SP): Editora Verus; 2003.

17. Reis HFT. Famílias de pessoas em sofrimento mental: um olhar fenomenológico sobre as relações de convivência [dissertação]. Jequié (BA): Universidade Estadual do Sudoeste da Bahia, Mestrado Enfermagem e Saúde; 2010.

18. Merleau-Ponty M. Fenomenologia da percepção. $3^{\mathrm{a}}$ ed. São Paulo (SP): Martins Fontes; 2006.

19. Chaves TV, Sanchez ZM, Ribeiro LA, Nappo SA. Fissura por crack: comportamentos e estratégias de controle de usuários. Rev Saúde Pública. 2011 Dez; 45(6):1168-75.

20. Seleghim MR, Marangon SL, Marcon SS, Oliveira MLF. Vínculo familiar de usuários de crack atendidos em uma unidade de emergência psiquiátrica. Rev Latino-Am Enferm. 2011 Set-Out; 19(5):1-8.

21. Sanchez ZVDM. As práticas religiosas atuando na recuperação de dependentes de drogas: a experiência de grupos católicos, evangélicos e espíritas [tese]. São Paulo (SP): Universidade Federal de São Paulo, Escola Paulista de Medicina; 2006. 